\title{
Coffee consumption, rheumatoid factor, and the risk of rheumatoid arthritis
}

\author{
M Heliövaara, K Aho, P Knekt, O Impivaara, A Reunanen, A Aromaa
}

\begin{abstract}
Background-Recent epidemiological studies have suggested that smoking is a risk factor for rheumatoid factor (RF) positive rheumatoid arthritis (RA). Being overweight, high serum cholesterol, and dietary factors have in some studies been found to be associated with the risk of RA. No attention, however, has been paid to coffee consumption as a risk determinant, though it is a shared covariate of the alleged risk factors.
\end{abstract}

Objectives-This study aimed at examining coffee consumption for its associations with RF positivity and with the risk of RA. Methods-Coffee consumption was studied, firstly, for its association with RF (sensitised sheep cell agglutination titre $\geqslant 128$ ) in a cross sectional survey of 6809 subjects with no clinical arthritis, and secondly, for its prediction of RA in a cohort of 18981 men and women who had neither arthritis nor a history of it at the baseline examination in 1973-76. Up to late 1989, 126 subjects of the cohort study had developed RA, of whom, 89 were positive for RF by the time of diagnosis.

Results-In the cross sectional survey the number of cups of coffee drunk daily was directly proportional to the prevalence of RF positivity. Adjusted for age and sex this association was significant ( $p$ value for linear trend, 0.008), but after further adjustment for smoking the linear trend declined below significance $(p=0.06)$. In the cohort study there was an association between coffee consumption and the risk of RF positive RA that was not due to age, sex, level of education, smoking, alcohol intake, body mass index, or serum cholesterol. After adjustment for these potential confounders the users of four or more cups a day still had a relative risk of 2.20 ( $95 \%$ confidence interval 1.13 to 4.27 ) for developing RF positive RA compared with those drinking less. Coffee consumption did not predict the development of RF negative RA.

Conclusion-Coffee consumption may be a risk factor for RA, possibly through mechanisms contributing to the production of RF. This hypothesis remains to be tested in further studies.

(Ann Rheum Dis 2000;59:631-635)

Dr M Heliövaara, National

Public Health Institute,

Mannerheimintie 166,

FIN-00300 Helsinki, Finland

Email

markku.heliovaara@ktl.fi

Accepted for publication

3 February 2000

Rheumatoid arthritis (RA) is a chronic inflammatory disease of unknown cause. Rheumatoid factor (RF), a hallmark antibody of RA, often precedes the onset of RA by years. ${ }^{1}$ In patients with RA, RF predicts progression of arthritis. ${ }^{2}$ Recent epidemiological studies have suggested that smoking is a risk factor for RF positive RA, in particular..$^{3-7}$ Smokers have also been shown to have an increased prevalence of RF positivity in the absence of clinical arthritis - that is, a "false positive" RF reaction. ${ }^{8}{ }^{9}$ Other obvious risk factors for RA are not known, though being overweight, ${ }^{510}$ high serum cholesterol, ${ }^{11}$ low serum antioxidant status, ${ }^{12}{ }^{13}$ low intake of olive oil, ${ }^{14}$ low consumption of fish, ${ }^{15}$ and history of blood transfusion ${ }^{5}$ have in some studies been found to be associated with the risk of RA.

No attention has been paid to coffee consumption as a possible risk determinant of RA, though it shows associations with smoking, ${ }^{16}$ serum cholesterol, ${ }^{17}$ and certain dietary factors. ${ }^{16}$ We studied coffee consumption for its association with $\mathrm{RF}$ in a cross sectional setting, and for its prediction of RA in a prospective study design.

\section{Patients and methods}

THE MINI-FINLAND HEALTH SURVEY

The cross sectional part of the current study was based on the Mini-Finland Health Survey. ${ }^{18}$ This comprehensive health survey, carried out between 1978 and 1980, was designed to assess the health of adult Finns. The study group was a two stage cluster sample drawn from the population register and stratified to represent Finns aged 30 years or over. The first stage comprised the selection of 40 representative areas. In the second stage a systematic sample of inhabitants was drawn from each area. The sample size was 8000, of whom $7217(90 \%)$ participated in the health examination.

The participants were first interviewed at home by local public health nurses and examined one to six weeks later by the mobile clinic of the Social Insurance Institution. Data on education, smoking, and consumption of coffee were obtained in the interview. The methods used for studying arthritis and the basic results of the Mini-Finland Health Survey have been described elsewhere. ${ }^{18} 19$ Arthritis was diagnosed on the basis of medical history, symptoms, physical examination, and hand radiographs, ${ }^{19}$ and the subjects with arthritis were excluded from the analyses of this study. The sensitised sheep cell agglutination test was performed for 6986 people free from clinical arthritis. ${ }^{8}{ }^{19}$ Among them, data on low density lipoprotein (LDL) cholesterol was available for 6809 subjects, who constituted the cross sectional study group.

The sensitised sheep cell agglutination test was performed on microtitre plates with $U$ shaped wells. Natural agglutinins were first 
Table 1 Rheumatoid factor positivity by consumption of coffee. Odds ratios with $95 \%$ confidence intervals (CI) adjusted for age and sex using logistic regression model

\begin{tabular}{|c|c|c|c|c|c|c|c|c|c|c|}
\hline \multirow{3}{*}{$\begin{array}{l}\text { Cups of } \\
\text { coffee a } \\
\text { day }\end{array}$} & \multirow{3}{*}{$\begin{array}{l}\text { Number of } \\
\text { subjects } \\
\text { examined }\end{array}$} & \multicolumn{9}{|c|}{ Sensitised sheep cell agglutination test } \\
\hline & & \multicolumn{3}{|l|}{ Titre $\geqslant 32$} & \multicolumn{3}{|l|}{ Titre $\geqslant 64$} & \multicolumn{3}{|l|}{ Titre $\geqslant 128$} \\
\hline & & $\begin{array}{l}\text { Number of } \\
\text { cases }\end{array}$ & $\begin{array}{l}\text { Odds } \\
\text { ratio }\end{array}$ & $95 \% C I$ & $\begin{array}{l}\text { Number of } \\
\text { cases }\end{array}$ & $\begin{array}{l}\text { Odds } \\
\text { ratio }\end{array}$ & $95 \% C I$ & $\begin{array}{l}\text { Number of } \\
\text { cases }\end{array}$ & Odds ratio & $95 \% C I$ \\
\hline 0 & 367 & 5 & 1.00 & & 3 & 1.00 & & 1 & 1.00 & \\
\hline 1 & 238 & 4 & 1.22 & 0.32 to 4.58 & 1 & 0.51 & 0.05 to 4.98 & 0 & Indetermin & ate \\
\hline 2 & 623 & 16 & 1.82 & 0.66 to 5.02 & 15 & 2.98 & 0.85 to 10.39 & 10 & 5.84 & 0.74 to 45.98 \\
\hline 3 & 698 & 18 & 1.90 & 0.70 to 5.19 & 13 & 2.38 & 0.67 to 8.45 & 7 & 3.80 & 0.46 to 31.09 \\
\hline 4 & 1128 & 19 & 1.21 & 0.45 to 3.29 & 10 & 1.10 & 0.30 to 4.05 & 7 & 2.30 & 0.28 to 18.80 \\
\hline 5 & 876 & 14 & 1.23 & 0.44 to 3.45 & 11 & 1.67 & 0.46 to 6.02 & 5 & 2.27 & 0.26 to 19.54 \\
\hline 6 & 1311 & 34 & 1.96 & 0.76 to 5.05 & 26 & 2.56 & 0.77 to 8.54 & 18 & 5.30 & 0.70 to 39.92 \\
\hline 7 & 275 & 3 & 0.85 & 0.20 to 3.60 & 3 & 1.43 & 0.29 to 7.17 & 2 & 2.90 & 0.26 to 32.23 \\
\hline 8 & 443 & 10 & 1.82 & 0.62 to 5.39 & 6 & 1.83 & 0.45 to 7.39 & 4 & 3.71 & 0.41 to 33.43 \\
\hline 9 & 92 & 2 & 1.64 & 0.31 to 8.61 & 1 & 1.38 & 0.14 to 13.46 & 1 & 4.17 & 0.26 to 67.44 \\
\hline 10 & 559 & 12 & 1.75 & 0.61 to 5.01 & 11 & 2.67 & 0.74 to 9.65 & 7 & 5.16 & 0.63 to 42.27 \\
\hline$\geqslant 11$ & 199 & 9 & 3.82 & 1.26 to 11.63 & 8 & 5.50 & 1.44 to 21.08 & 7 & 14.80 & 1.80 to 121.79 \\
\hline \multicolumn{3}{|c|}{ p Value for linear trend ${ }^{\star}$} & 0.10 & & & 0.04 & & & 0.008 & \\
\hline \multicolumn{3}{|c|}{ p Value for departure from linearity ${ }^{\star}$} & 0.48 & & & 0.44 & & & 0.50 & \\
\hline
\end{tabular}

^Likelihood ratio test based on logistic regression model.

absorbed from the serum to be tested. Sheep red blood cells were sensitised with one third of the minimum agglutinating dose of amboceptor, obtained by prolonged immunisation. The plates were stored overnight at $4^{\circ} \mathrm{C}$ in a refrigerator, after which the readings were made on the basis of sedimentation patterns. Serum cholesterol was determined by an autoanalyser modification of the Lieberman-Burchard method and serum triglycerides by an enzymatic method. For the determination of high density lipoprotein (HDL) cholesterol, LDL and very low density lipoprotein cholesterols were precipitated with magnesium dextran sulphate. The LDL cholesterol concentration was estimated with the formula of Friedewald et a ${ }^{20}$ for subjects with serum triglyceride concentrations below $4.0 \mathrm{mmol} / 1$.

MOBILE CLINIC HEALTH EXAMINATION SURVEY The prospective part of the current study was based on the Mobile Clinic Health Examination Survey. ${ }^{21}$ Between 1973 and 1977 the Social Insurance Institution's mobile clinic carried out health examinations in 12 municipalities in four regions of Finland. The main emphasis was on the risk factors for cardiovascular disorders. In each of the four geographic regions, all inhabitants or a random sample of inhabitants of one rural municipality and one urban or semi-urban municipality as well as the employees of one factory were invited to attend the examination. A total of 19518 men and women aged 20 years or over $(83 \%$ of those invited) participated in the examinations. The mean age of the subjects was 45 (range 20-98).

A questionnaire with items about socioeconomic background, medical history, smoking, consumption of alcohol and coffee, and use of sugar in coffee was sent to the subjects together with an invitation to attend the medical check up. The answers to this self filled questionnaire were checked and completed, if necessary, by a specially trained nurse who interviewed the participants at the mobile clinic. Serum total cholesterol was determined using an autoanalyser modification of the Lieberman-Burchard method.
COFFEE CONSUMPTION AND ITS RELIABILITY

In both surveys the habitual consumption of coffee was determined by asking "How many cups of coffee a day do you drink on average?" In the Mini-Finland Health Survey the interview was repeated about three months later in a random sample of 338 subjects. The intraclass correlation coefficient for daily cups of coffee between the interviews was 0.81 . In a sample of 267 participants of the Mobile Clinic Health Examination Survey, the intraclass correlation coefficient was still as high as 0.74 after about half a year. There was also good agreement between baseline and repeat questionnaires in identifying those consuming four or more cups daily $(\kappa=0.70)$.

\section{INCIDENCE OF RA}

Morbidity and mortality of all examinees has been followed up continuously. Participants in the Mobile Clinic Health Examination Survey who later developed chronic arthritis were identified by linking the survey data with the Social Insurance Institution's population register up to the end of 1989 , using the unique social security code assigned to each Finnish citizen. In Finland reimbursed drug treatment is provided for certain chronic diseases, including chronic inflammatory rheumatic diseases. Eligibility requires a comprehensive medical certificate written by the attending doctor. These documents were carefully reviewed to identify incident cases of RA. ${ }^{3}$ Information on the RF status by the time of RA diagnosis was also obtained from the certificates. The tests had been performed in several laboratories.

Most patients with RA entitled to reimbursement for drug treatment meet the revised criteria of the American Rheumatism Association, and the sensitivity of the sickness insurance data exceeds $90 \%$ for seropositive RA. ${ }^{322}$

\section{STATISTICAL ANALYSIS}

A number of factors may be associated with coffee consumption and both RF or RA and might therefore confound the analysis. In previous studies the level of education, body mass index, serum cholesterol concentration, smoking, and alcohol intake have been shown to be associated with the occurrence of RF or 
Table 2 Adjusted ${ }^{\star}$ odds ratio (with 95\% confidence interval (CI)) of rheumatoid factor (RF) positivity (sensitised sheep cell agglutination titre $\geqslant 128$ ) for different factors

\begin{tabular}{|c|c|c|c|c|c|c|}
\hline Factor & Unit or category & $\begin{array}{l}\text { Number of } \\
\text { subjects } \\
\text { examined }\end{array}$ & $\begin{array}{l}\text { Number of } \\
R F \text { positive } \\
\text { cases }\end{array}$ & $\begin{array}{l}\text { Odds } \\
\text { ratio }\end{array}$ & $95 \% C I$ & $p$ Valuet \\
\hline Consumption of coffee & For each SD, 2.8 cups & 6809 & 69 & 1.24 & 0.97 to 1.58 & 0.09 \\
\hline Age & For each SD, 14.1 years & 6809 & 69 & 1.41 & 1.09 to 1.83 & 0.01 \\
\hline \multirow[t]{2}{*}{ Sex } & Men & 3132 & 37 & 1.00 & & \\
\hline & Women & 3677 & 32 & 1.31 & 0.75 to 2.28 & 0.34 \\
\hline Serum LDL cholesterol $\ddagger$ & For each SD, $1.2 \mathrm{mmol} / 1$ & 6809 & 69 & 1.28 & 1.04 to 1.59 & 0.03 \\
\hline \multirow[t]{5}{*}{ Smoking } & Never smoked & 3789 & 21 & 1.00 & & \multirow{5}{*}{0.0003} \\
\hline & Quit & 1414 & 18 & 2.78 & 1.36 to 5.69 & \\
\hline & Cigars, pipe or & & & & & \\
\hline & $<20$ Cigarettes/day & 1004 & 20 & 4.32 & 2.19 to 8.54 & \\
\hline & $\geqslant 20$ Cigarettes/day & 602 & 10 & 3.77 & 1.57 to 9.04 & \\
\hline
\end{tabular}

^All variables in the table were included in the logistic regression model.

†Likelihood ratio test for linear trend (continuous variables) or for heterogeneity (groups of categorised variables). $\ddagger$ LDL cholesterol = low density lipoprotein cholesterol.

$\mathrm{RA}^{3581023}$ and to covary with coffee drinking. ${ }^{16}{ }^{17}$ These factors, in addition to sex and age, were therefore considered potential confounders or effect modifiers in this study.

The general linear model was used to compute multiple partial correlation ratios between coffee consumption and the potential confounding factors. ${ }^{24}$ The logistic regression model was used to estimate the associations between coffee consumption and the occurrence of $\mathrm{RF}^{25}$ The Cox life table regression model was used to analyse coffee consumption for its prediction of RA. ${ }^{26}$ Both confounding and effect-modifying factors were entered into these models, and the significance of covariate terms was evaluated by the likelihood ratio test. Tests for trend were conducted by including explanatory factors as continuous variables in the model.

\section{Results}

THE CROSS SECTIONAL STUDY ON COFFEE

CONSUMPTION AND RF

The number of cups of coffee taken daily was found to be directly proportional to the prevalence of RF (table 1). This association was the stronger the higher the cut off level for RF positivity. Adjusted for age and sex, the relation between coffee consumption and the prevalence of sensitised sheep cell agglutination titre $\geqslant 128$ was significant ( $p$ value for linear trend, 0.008) and the odds ratio of RF in subjects reporting an intake of 11 or more cups daily was 14.80 (95\% confidence interval (CI) 1.80 to 121.79 ) compared with those reporting no intake.
Age, serum LDL cholesterol, and smoking, independently of each other, were positively associated with the prevalence of sensitised sheep cell agglutination titre $\geqslant 128$ (table 2 ). These factors also correlated significantly $(\mathrm{p}<0.001)$ with the number of cups of coffee taken daily: partial correlation ratios with coffee consumption adjusted for all the potential covariates considered in this study were -0.09 for age, 0.05 for LDL cholesterol, and 0.12 for smoking. The significance of the association between coffee consumption and the prevalence of RF positivity was lost when smoking was entered into the model ( $p$ value for linear trend, 0.06), and adjustment for LDL cholesterol reduced the significance further $(\mathrm{p}$ value for linear trend, 0.08 ). The level of education, body mass index, serum HDL cholesterol, or alcohol intake neither determined RF nor confounded the association between coffee and RF. No significant interaction was found between coffee consumption and the other factors that affected the prevalence of $\mathrm{RF}$, and the association between coffee drinking and RF seemed consistent between all strata of the potential confounders (data not shown).

\section{THE COHORT STUDY ON COFFEE CONSUMPTION} AND RA INCIDENCE

The number of cups of coffee taken daily significantly predicted the development of RF positive RA but not RF negative RA (table 3 ). As the relation departed significantly from linearity $(p=0.02)$, the distribution of coffee con-

Table 3 Age and sex adjusted relative risks (with 95\% confidence intervals (CI)) of developing rheumatoid factor (RF) positive rheumatoid arthritis $(R A), R F$ negative $R A$, and $R A$ in total by consumption of coffee

\begin{tabular}{|c|c|c|c|c|c|c|c|c|c|c|}
\hline \multirow{2}{*}{$\begin{array}{l}\text { Cups of } \\
\text { coffee a } \\
\text { day }\end{array}$} & \multirow{2}{*}{$\begin{array}{l}\text { Number of } \\
\text { subjects } \\
\text { examined }\end{array}$} & \multicolumn{3}{|c|}{$R F$ positive $R A$} & \multicolumn{3}{|c|}{$R F$ negative $R A$} & \multicolumn{3}{|c|}{$R A$ in total } \\
\hline & & $\begin{array}{l}\text { Number of } \\
\text { cases }\end{array}$ & $\begin{array}{l}\text { Relativ } \\
\text { risk }\end{array}$ & $95 \% C I$ & $\begin{array}{l}\text { Number of } \\
\text { cases }\end{array}$ & $\begin{array}{l}\text { Relative } \\
\text { risk }\end{array}$ & $95 \% C I$ & $\begin{array}{l}\text { Number } \\
\text { of cases }\end{array}$ & $\begin{array}{l}\text { Relative } \\
\text { risk }\end{array}$ & $95 \% C I$ \\
\hline 0 & 996 & 1 & \multicolumn{2}{|l|}{1.00} & 1 & \multicolumn{2}{|l|}{1.00} & 2 & \multicolumn{2}{|l|}{1.00} \\
\hline 1 & 564 & 0 & \multicolumn{2}{|c|}{ Indeterminate } & 3 & 5.46 & 0.57 to 52.59 & 3 & 2.72 & 0.45 to 16.29 \\
\hline 2 & 1438 & 4 & \multicolumn{2}{|r|}{0.31 to 24.60} & 3 & \multicolumn{2}{|r|}{0.21 to 19.45} & 7 & 2.39 & 0.50 to 11.52 \\
\hline 3 & 1643 & 5 & 2.84 & 0.33 to 24.35 & 1 & 0.54 & 0.03 to 8.68 & 6 & 1.68 & 0.34 to 8.35 \\
\hline 4 & 2994 & 13 & 3.87 & 0.51 to 29.64 & 5 & 1.39 & 0.16 to 11.90 & 18 & & 0.61 to 11.33 \\
\hline 5 & 2383 & 18 & 6.82 & 0.91 to 51.13 & 5 & 1.79 & 0.21 to 15.39 & 23 & & 1.01 to 18.21 \\
\hline 6 & 4157 & 20 & 4.24 & 0.57 to 31.65 & 9 & 1.79 & 0.23 to 14.20 & 29 & $\begin{array}{l}4.29 \\
3.02\end{array}$ & 0.72 to 12.67 \\
\hline 7 & 783 & 4 & 4.62 & 0.52 to 41.40 & 1 & 1.11 & 0.07 to 17.82 & 5 & 2.86 & 0.55 to 14.75 \\
\hline 8 & 1686 & 12 & 6.48 & 0.84 to 49.84 & 5 & 2.63 & 0.31 to 22.53 & 17 & 4.55 & 1.05 to 19.72 \\
\hline 9 & 260 & 2 & 6.70 & 0.61 to 73.97 & 1 & 3.15 & 0.20 to 50.58 & 3 & 4.93 & 0.82 to 29.57 \\
\hline 10 & 1611 & 10 & 6.07 & 0.78 to 47.39 & 3 & 1.83 & 0.19 to 17.62 & 13 & \multicolumn{2}{|r|}{0.89 to 17.51} \\
\hline$\geqslant 11$ & 466 & 0 & \multicolumn{2}{|c|}{ Indeterminate } & 0 & \multicolumn{2}{|c|}{ Indeterminate } & 0 & \multicolumn{2}{|c|}{ Indeterminate } \\
\hline \multicolumn{3}{|c|}{$\mathrm{p}$ Value for trend ${ }^{\star}$} & \multicolumn{2}{|l|}{0.02} & & \multicolumn{2}{|l|}{0.88} & & \multicolumn{2}{|l|}{0.04} \\
\hline \multicolumn{3}{|c|}{ p Value for departure from linearity ${ }^{\star}$} & \multicolumn{2}{|l|}{0.02} & & \multicolumn{2}{|l|}{0.92} & & \multicolumn{2}{|l|}{0.07} \\
\hline
\end{tabular}

${ }^{\star}$ Likelihood ratio test based on Cox model. 
Table 4 Adjusted ${ }^{\star}$ relative risk (with 95\% confidence interval (CI)) of developing rheumatoid factor positive rheumatoid arthritis for different factors

\begin{tabular}{|c|c|c|c|c|c|c|}
\hline Factor & Unit or category & $\begin{array}{l}\text { Number of } \\
\text { subjects } \\
\text { examined }\end{array}$ & $\begin{array}{l}\text { Number of } \\
\text { incident cases }\end{array}$ & $\begin{array}{l}\text { Relative } \\
\text { risk }\end{array}$ & $95 \% C I$ & $p$ Valuet \\
\hline \multirow[t]{2}{*}{ Consumption of coffee } & $\leqslant 3 \mathrm{Cups} /$ day & 4641 & 10 & 1.00 & & \\
\hline & $\geqslant 4 \mathrm{Cups} /$ day & 14340 & 79 & 2.20 & 1.13 to 4.27 & 0.01 \\
\hline Age & For each SD, 15.4 years & 18981 & 89 & 1.20 & 0.91 to 1.59 & 0.19 \\
\hline Body mass index & For each SD, $4.1 \mathrm{~kg} / \mathrm{m}^{2}$ & 6809 & 69 & 1.11 & 0.89 to 1.37 & 0.36 \\
\hline Serum cholesterol & For each SD, $1.4 \mathrm{mmol} / 1$ & 18981 & 89 & 1.00 & 0.79 to 1.26 & 0.99 \\
\hline \multirow[t]{2}{*}{ Sex } & Men & 9705 & 31 & 1.00 & & \\
\hline & Women & 9276 & 58 & 2.58 & 1.48 to 4.50 & 0.0007 \\
\hline \multirow[t]{3}{*}{ Level of education } & $0-8$ years & 12435 & 64 & 1.00 & & \\
\hline & $9-12$ years & 5368 & 19 & 0.77 & 0.45 to 1.32 & 0.56 \\
\hline & $\geqslant 13$ years & 1178 & 6 & 1.14 & 0.48 to 2.68 & \multirow{7}{*}{0.14} \\
\hline \multirow[t]{6}{*}{ Smoking } & Never smoked & 10067 & 46 & 1.00 & & \\
\hline & Quit & 3411 & 16 & 1.76 & 0.92 to 3.38 & \\
\hline & Cigars, pipe or & & & & & \\
\hline & $\leqslant 14$ Cigarettes/day & 2718 & 11 & 1.28 & 0.63 to 2.57 & \\
\hline & 15-24 Cigarettes/day & 2252 & 12 & 2.28 & 1.07 to 4.85 & \\
\hline & $\geqslant 25$ Cigarettes/day & 533 & 4 & 3.43 & 1.10 to 10.70 & \\
\hline \multirow[t]{4}{*}{ Intake of alcohol } & Not at all & 8026 & 40 & 1.00 & & \multirow{4}{*}{0.97} \\
\hline & 1-99 grams/month & 3383 & 18 & 1.15 & 0.64 to 2.05 & \\
\hline & $100-499$ grams/month & 5180 & 22 & 1.09 & 0.59 to 2.10 & \\
\hline & $\geqslant 500 \mathrm{grams} / \mathrm{month}$ & 2392 & 9 & 1.04 & 0.44 to 2.50 & \\
\hline
\end{tabular}

*All variables in the table were included in the Cox model.

†Likelihood ratio test for linear trend (continuous variables) or for heterogeneity (groups of categorised variables).

sumption was dichotomised into the users of four or more cups daily and those drinking less.

Body mass index, serum total cholesterol, alcohol consumption, and smoking, independently of age, sex, and each other, correlated positively with the daily number of cups of coffee. All partial correlations, albeit modest, were significant $(p<0.001)$. The highest correlation ratio $(r=0.16)$ was obtained for smoking. Smoking was also a significant predictor of RF positive RA (table 4). After adjustment for the potential confounders, however, the users of four or more cups daily still had a relative risk of 2.20 (95\% CI 1.13 to 4.27) of developing RF positive RA, compared with those drinking fewer than four cups (table 4). The corresponding relative risk of RA in total was 1.69 (95\% CI 1.02 to 2.80 ).

The association between coffee consumption and the risk of RF positive RA seemed to vary in strength between different subsections of the study group and categories of the potential confounders, but no significant interaction was found (table 5). Of note is that the association was strong and statistically significant among never-smokers.

To eliminate a possible bias due to early but still undiagnosed RA, the analysis was repeated after stratification taking into account the time between the baseline examination and the development of RA. When the first five years of follow up were excluded and adjustment made for age and sex, the subjects consuming four or more cups of coffee a day still had a relative risk of 2.06 (95\% CI 1.02 to 4.16 ) of developing RF positive RA compared with those who consumed fewer than four cups.

\section{Discussion}

If coffee consumption were to show a modest association with either RF or RA, the most likely explanation for such a finding would be confounding or chance alone. That our main results, from two independent studies with different designs and outcomes, point to the same inference clearly suggests that the phenomenon is real, even if its mechanism remains unknown. Against this background, our results should be viewed as the first step in support of the hypothesis that coffee consumption has a causative role in the development of RF positive RA.

Finland ranks high among countries in coffee consumption, and the tradition of drinking coffee permeates all social strata. The Finnish population is therefore well suited for studying dose-response associations of coffee use. The sample of the Mini-Finland Health Survey was representative of the Finnish adult population. ${ }^{18}$ In the Mobile Clinic Health

Table 5 Age and sex adjusted relative risk (with 95\% confidence interval (CI)) of developing rheumatoid factor positive rheumatoid arthritis in people taking $\geqslant 4$ cups of coffee a day, compared with those taking $\leqslant 3$ cups a day, in strata of different factors

\begin{tabular}{|c|c|c|c|c|c|c|}
\hline Factor & Stratum & $\begin{array}{l}\text { Number of } \\
\text { subjects } \\
\text { examined }\end{array}$ & $\begin{array}{l}\text { Number of } \\
\text { incident cases }\end{array}$ & $\begin{array}{l}\text { Relative } \\
\text { risk }\end{array}$ & $95 \% C I$ & $\begin{array}{l}p \text { Value for } \\
\text { interaction }\end{array}$ \\
\hline \multirow[t]{2}{*}{ Age } & $<50$ years & 11956 & 58 & 2.14 & 0.96 to 4.77 & \\
\hline & $\geqslant 50$ years & 7025 & 31 & 2.30 & 0.70 to 7.61 & 0.24 \\
\hline \multirow[t]{2}{*}{ Sex† } & Men & 9705 & 31 & 3.40 & 1.03 to 11.24 & \\
\hline & Women & 9276 & 58 & 1.99 & 0.90 to 4.38 & 0.93 \\
\hline \multirow[t]{2}{*}{ Serum cholesterol } & $<7.0 \mathrm{mmol} / 1$ & 11363 & 52 & 1.98 & 0.93 to 4.22 & \\
\hline & $\geqslant 7.0 \mathrm{mmol} / 1$ & 7618 & 37 & 3.97 & 0.95 to 16.50 & 0.78 \\
\hline \multirow[t]{3}{*}{ Smoking } & Never smoked & 10067 & 46 & 3.07 & 1.10 to 8.59 & \\
\hline & Quit & 3411 & 16 & 1.44 & 0.41 to 5.07 & 0.94 \\
\hline & Current smokers & 5503 & 27 & 1.90 & 0.57 to 6.39 & \\
\hline \multirow[t]{2}{*}{ Use of sugar in coffee } & No & 5650 & 21 & 9.16 & 1.22 to 68.63 & \\
\hline & Yes & 13331 & 68 & 1.56 & 0.77 to 3.15 & 0.23 \\
\hline
\end{tabular}

${ }^{\star}$ Each factor $\times$ coffee; likelihood ratio test based on Cox model.

tAdjusted for age only. 
Examination Survey, each of the 12 study groups was representative of the community from which it was drawn, ${ }^{21}$ and the high participation rates allow us to generalise about the results. The background information elicited in the surveys covers most of the alleged risk factors for RA.

Habitual coffee drinking may be a poor and biased estimate of lifetime coffee consumption. ${ }^{27}$ In both surveys of the current study, however, subjects' initial estimates of their daily coffee consumption agreed well with subsequent estimates made three to six months later. Furthermore, a reduced contrast between heavy and light coffee consumption is likely to underestimate rather than overestimate the associations of the risk determinant with RF and RA.

As expected, smoking was found to confound the associations between coffee and RF and RA. In particular, the relation between coffee consumption and the prevalence of RF was no longer significant after the adjustment for smoking. Coffee use, however, was a significant predictor of RF positive RA even in never-smokers, which clearly indicates an independent role for coffee.

The positive association found in the current study between serum LDL cholesterol and RF points the way for further research. In Finland more than three quarters of coffee consumers have switched from boiled coffee to filtered coffee since the 1970s. The proportion of people consuming boiled coffee was $25 \%$ in 1987 and only $15 \%$ in 1993, a shift accompanied by a significant parallel decrease of serum cholesterol level in the population. ${ }^{17}$ During the same period, from 1975 to 1990 , the mean age of diagnosis of RA increased from 50.2 to 57.8 years. ${ }^{28}$ The type of coffee consumed should therefore be considered in further studies on the relation between coffee and RA. Possibly, some ingredient in coffee, unidentified so far and removable by filtration, like the LDL-raising diterpenes ${ }^{29}$ might trigger the production of RF.

None of the risk factors for RA has been firmly ascertained in epidemiological studies. The aetiological research, including this study with its inevitable problems of causal inference, therefore remains explorative. It cannot be concluded whether the associations between coffee consumption and RF and RA were due to coffee exposure itself or to some lifestyle or dietary factor closely linked with it. Even selecting potential confounders and effect modifiers for inclusion in the explanatory models is problematic because the mutual relations of candidate factors are poorly understood and all risk determinants and latent variables obviously are not known. Thus new information is urgently needed about any factor associated with the risk of RA, whether alleged risk factor or confounder.

Our results suggest that coffee consumption may be a risk factor for RF positive RA. As RF often precedes $\mathrm{RA}^{1}$ the association between coffee consumption and RA risk may be mediated through mechanisms contributing to the production of RF. Whatever the mechanism, coffee consumption should be considered a possible risk factor or a confounder in future research into the cause of RA.
1 Aho K, Palosuo T, Kurki P. Marker antibodies of rheumatoid arthritis: diagnostic and pathogenetic implications. Semin Arthritis Rheum 1996;23:379-87.

2 Wolfe F. The natural history of rheumatoid arthritis. J Rheumatol 1996;23(suppl 44):13-22.

3 Heliövaara M, Aho K, Aromaa A, Knekt P, Reunanen A. Smoking and risk of rheumatoid arthritis. J Rheumatol 1993;20:1830-5.

4 Deighton C. Smoke gets in your joints? Ann Rheum Dis 1997;56:453-4.

5 Symmons DPM, Bankhead CR, Harrison BJ, Brennan P, Barrett EM, Scott DGI, et al. Blood transfusion, smoking, and obesity as risk factors for the development of rheumatoid arthritis. Results from a primary care-based incident case-control study in Norfolk, England. Arthritis Rheum 1997;40:1955-61.

6 Uhlig T, Hagen KB, Kvien TK. Current tobacco smoking, formal education, and the risk of rheumatoid arthritis. J Rheumatol 1999;26:47-54.

7 Wilson K, Goldsmith CH. Does smoking cause rheumatoid arthritis? J Rheumatol 1999;26:1-3.

8 Tuomi T, Heliövaara M, Palosuo T, Aho K. Smoking, lung function, and rheumatoid factors. Ann Rheum Dis 1990;49:753-6.

9 Jónsson T, Thorsteinsson J, Valdimarsson H. Does smoking stimulate rheumatoid factor production in non-rheumatic individuals? APMIS 1998;106:970-4

10 Voigt LF, Koepsell TD, Nelson JL, Dugowson CE, Daling JR. Smoking, obesity, alcohol consumption, and the risk of rheumatoid arthritis. Epidemiology 1994;5:525-32.

11 Heliövaara M, Aho K, Knekt P, Reunanen A, Aromaa A. Serum cholesterol and risk of rheumatoid arthritis in a cohort of 52800 men and women. Br J Rheumatol 1996;35:255-7.

12 Heliövaara M, Knekt P, Aho K, Aaran R-K, Alfthan G, Aromaa A. Serum antioxidants and risk of rheumatoid arthritis. Ann Rheum Dis 1994;53:51-3.

13 Comstock GW, Burke AE, Hoffman SC, Helzlsouer KJ, Bendich A, Masi AT, et al. Serum concentrations of $\alpha$ tocopherol, $\beta$ carotene, and retinol preceding the diagnosis of rheumatoid arthritis and systemic lupus erythematosus. Ann Rheum Dis 1997;56:323-5.

14 Linos A, Kaklamanis E, Kontomerkos A, Koumantaki Y, Gazi S, Vaiopoulos G, et al. The effect of olive oil and fish consumption on rheumatoid arthritis - a case control study. Scand J Rheumatol 1991;20:419-26.

15 Shapiro JA, Koepsell TD, Voigt LF, Dugowson CE, Kestin M, Nelson JL. Diet and rheumatoid arthritis in women: a possible protective effect of fish consumption. Epidemiology 1996;7:256-63.

16 Schreiber GB, Robins M, Maffeo CE, Master MN, Bond $\mathrm{AP}$, Morganstein D. Confounders contributing to the reported associations of coffee or caffeine with disease. Prev Med 1988;17:295-309.

17 Aro A. The effect of coffee on serum lipids and its clinical considerations. Cardiovascular Risk Factors 1993;3:23843.

18 Aromaa A, Heliövaara M, Impivaara O, Knekt P, Maatela J, Joukamaa $M$, et al. Health, functional limitations and need for care in Finland. Basic results from the Mini-Finland Health Survey. Helsinki and Turku: Publications of the Health Survey. Helsinki and Turku: Publications of the
Social Insurance Institution AL:32, 1989. (In Finnish with English summary.)

19 Aho A, Heliövaara $M$, Sievers $K$, Maatela J, Isomäki $H$. Clinical arthritis associated with positive radiological and serological findings in Finnish adults. Rheumatol Int 1989; 9:7-11.

20 Friedewald WT, Levy RJ, Fredrichson DS. Estimation of the concentration of low-density lipoprotein cholesterol in plasma, without use of the preparative ultracentrifuge. Clin plasma, without use of the

21 Reunanen A, Aromaa A, Pyörälä K, Punsar S, Maatela J, Knekt P. The Social Insurance Institution's coronary heart disease study. Baseline data and 5-years mortality experience. Acta Med Scand 1983;214(suppl 673):1-120.

22 Hakala M, Pöllänen R, Nieminen P. The ARA 1987 revised criteria select clinical rheumatoid arthritis from a population-based cohort of subjects with chronic rheupopulation-based cohort of subjects with chronic rheumatol 1993;20:1674-8.

23 Lawrence JS. Rheumatism in populations. London: Heinemann, 1977:156-271.

24 Searle SR. Linear models. New York: Wiley, 1971.

25 Breslow NE, Day NE. Statistical methods in cancer research. Vol 1. The analysis of case-control studies. Lyon: IARC Scientific Publications, 1980:248-79.

26 Cox DR. Regression models and life-tables. Journal of the Royal Statistical Society B 1972;34:187-220.

27 Hughes JR, Oliveto AH. A systematic survey of caffeine intake in Vermont. Experimental and Clinical Psychopharmacology 1997;5:393-8.

28 Kaipiainen-Seppänen O, Aho K, Isomäki H, Laakso M. Shift in the incidence of rheumatoid arthritis toward elderly patients in Finland during 1975-1990. Clin Exp Rheumatol 1996;14:537-42.

29 Heckers H, Gobel U, Kleppel U. End of the coffee mystery; diterpene alcohols raise serum low-density lipoprotein cholesterol and triglyceride levels. J Intern Med 1994;235: $192-3$. 